\title{
Description of the Determination Processes for the Typical Research and Development Intensity Normative Indicators
}

\author{
Sergey Novikov ${ }^{1} \&$ Andrey Sazonov $^{1}$ \\ ${ }^{1}$ Moscow Aviation Institute, National Research University, Moscow, Russian Federation \\ Correspondence: Sergey Novikov, Moscow Aviation Institute, National Research University, Moscow, 4, \\ Volokolamskoe Highway, 125993, Russian Federation. Tel: 7-916-641-5891. E-mail: danonik92@mail.ru, \\ ncsrm@mail.ru
}

Received: December 16, 2019

Accepted: February 3, $2020 \quad$ Online Published: March 5, 2020

doi:10.5430/rwe.v11n1p64

URL: https://doi.org/10.5430/rwe.v11n1p64

\begin{abstract}
The article is devoted to description of the determination processes for the typical research and development (R\&D) intensity normative indicators. In the theoretical part, the authors consider the standards system formation and labor costs norms for R\&D. The main composit element (CE) hierarchy of the R\&D technology is given. The scheme of the development algorithm for the R\&D labor costs standards is drawn. The labor costs norming technique for research works is considered. The procedure for determining the labor costs normative volume for a standardized object is determined. In the research part, the article's authors examined the automated system components used to determine labor intensity forecast indicators in the product life cycle information support. The process of determining the normative labor costs volume based on eight consecutive stages is presented. The database composition necessary for the product life cycle information support is described. Modules for projects' planning and monitoring in the automated system framework are considered structurally. The modules' composition used for the analysis of production systems and forecasting production economic indicators is determined. The regulatory requirements for the production's modules for technological support and technical regulation are given as part of the automated system work for determining labor intensity forecast indicators in the product life cycle information support. The article concludes with an algorithm for estimating the R\&D work clusters' cost and the aircraft's distributed systems creation and development.
\end{abstract}

Keywords: organization of R\&D, automated systems, work labor intensity calculation, labor costs norming technique, $R \& D$ costs calculation

\section{Introduction}

The system of labor costs norms and standards for R\&D is a set of standards and norms covering all CE R\&D aggregation levels and all $\mathrm{R} \& \mathrm{D}$ and all $\mathrm{R} \& \mathrm{D}$ classification groups, which allows to evaluate the labor costs volume, the distribution of these volumes by type of works, as well as the minimum duration for all planning and accounting units necessary and sufficient for planning at all levels of R\&D process control. The system of labor costs norms and standards for R\&D is a part of the R\&D labor standards and R\&D norms system and includes the following types of standards and norms (Ministry of Science and Higher Education, 2019):

- labor costs norms and standards;

- norms and standards of labor costs volume ratios by type of works;

- work duration norms and standards performed as a part of R\&D.

The norms and standards system of R\&D labor costs is the main element of the regulatory framework for planning $\mathrm{R} \& \mathrm{D}$ labor costs. Under the regulatory framework the system of standards and norms totality for reference information of R\&D labor costs is being understood, necessary for the standards and norms development and improvement; organizational and administrative and normative-methodological documentation providing a unified procedure for the creation, standards' and norms' implementation and improvement and a single methodological approach to the standards' development and use. The labor costs norming process for R\&D and the work performed within it includes two main stages (Vilensky, Kaloshina, Livshits, Orlova, Smolyak \& Trofimova, 2002):

- $\quad$ standards development; 
- $\quad$ standards' use and adjustment.

Labor costs R\&D standards and norms of are classified according to the following criteria:

- $\quad$ application objects group;

- $\quad$ E research aggregation level;

- development aggregation level;

- type of work;

- approval level;

- development method and validity.

The standards classification by approval levels is based on a hierarchical principle (Ermakova, 2017):

- intersectoral standards;

- $\quad$ industry standards;

- local regulations.

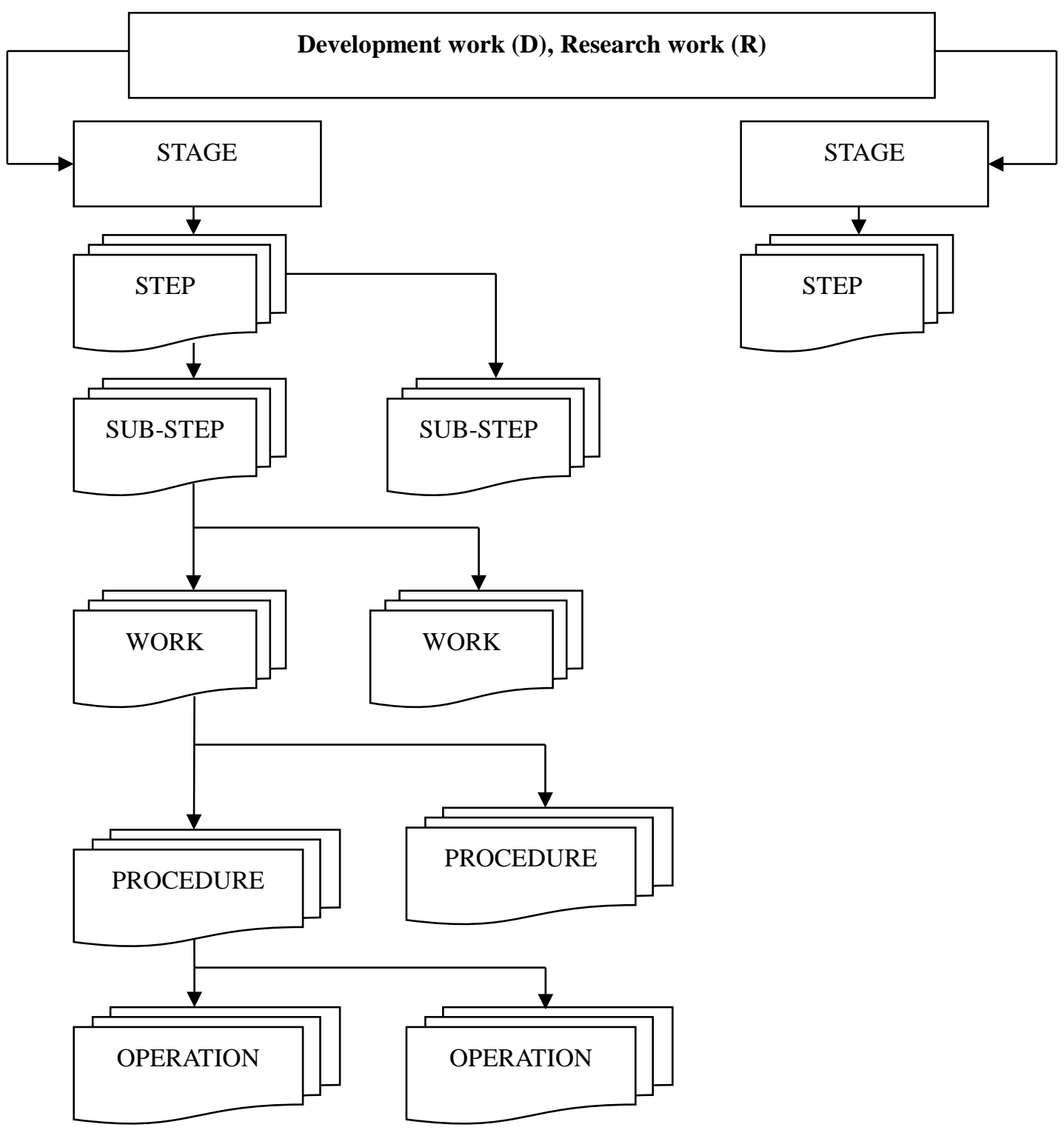

Figure 1. R\&D's technology CE hierarchy 
Intersectoral and industry standards are divided into single and standard. The division of intersectoral and industry standards into uniform and standard is determined by their scope (Bokov, \& Podolsky, 2015; Dmitriev \& Novikov, 2019):

- single standards are developed at R, D and R\&D's CE which are carried out according to the same technology and in the same organizational and technical conditions in a number of sectors of the economy or in one industry;

- standard standards are at R, D and R\&D's CE, which are carried out according to standard technology, taking into account the progressive organizational and technical conditions that already exist in most or part of enterprises where such developments are carried out.

Local standards are developed in the absence of appropriate intersectoral or sectoral ones, as well as when creating more advanced R\&D organizational and technical conditions in the company compared with those available when developing intersectoral and industry standards. Standards classification by the development method is carried out in accordance with which of the methods regulated by this R\&D, expert or experimental-statistical is used to obtain and process the source data in the standards development.

Standards ought to satisfy the requirements of progressiveness, reliability, comparability, and interoperability. The standards' progressiveness is understood as their orientation towards the R\&D's use of advanced techniques and methods for achieving the set goal and organizational and technical conditions in the R\&D performing process. The standards' progressiveness is supported by their systematic updating (adjustment) based on the scientific and technological progress factors' consideration, R\&D organizing advanced methods, and labor organization.

Reliability means that the degree of compliance with standards meets the combined labor costs standards, objectively necessary to carry out work on normalized planned accounting with a given quality. Reliability is ensured by an objective consideration of R\&D work and the organizational and technical support level for R\&D. Comparability refers to the possibility of comparing labor costs standards for similar planning and accounting units performed by various departments or various enterprises. Comparability is ensured by the unified classification of R\&D's CE and R\&D for the industry, a unified information base and the use of a unified methodology for developing standards. The standard development algorithm is presented by diagrams in Figure 2. The standard development stage includes six stages (Government of the Russian Federation, 2011).

The first stage of the standards' development is the classification, R\&D classification groups' system formation, and typical representatives for each group definition. The basis of R\&D classification is a set of criteria on the basis of which classifiable objects are evaluated and a decision is made on belonging to a particular classification group. 


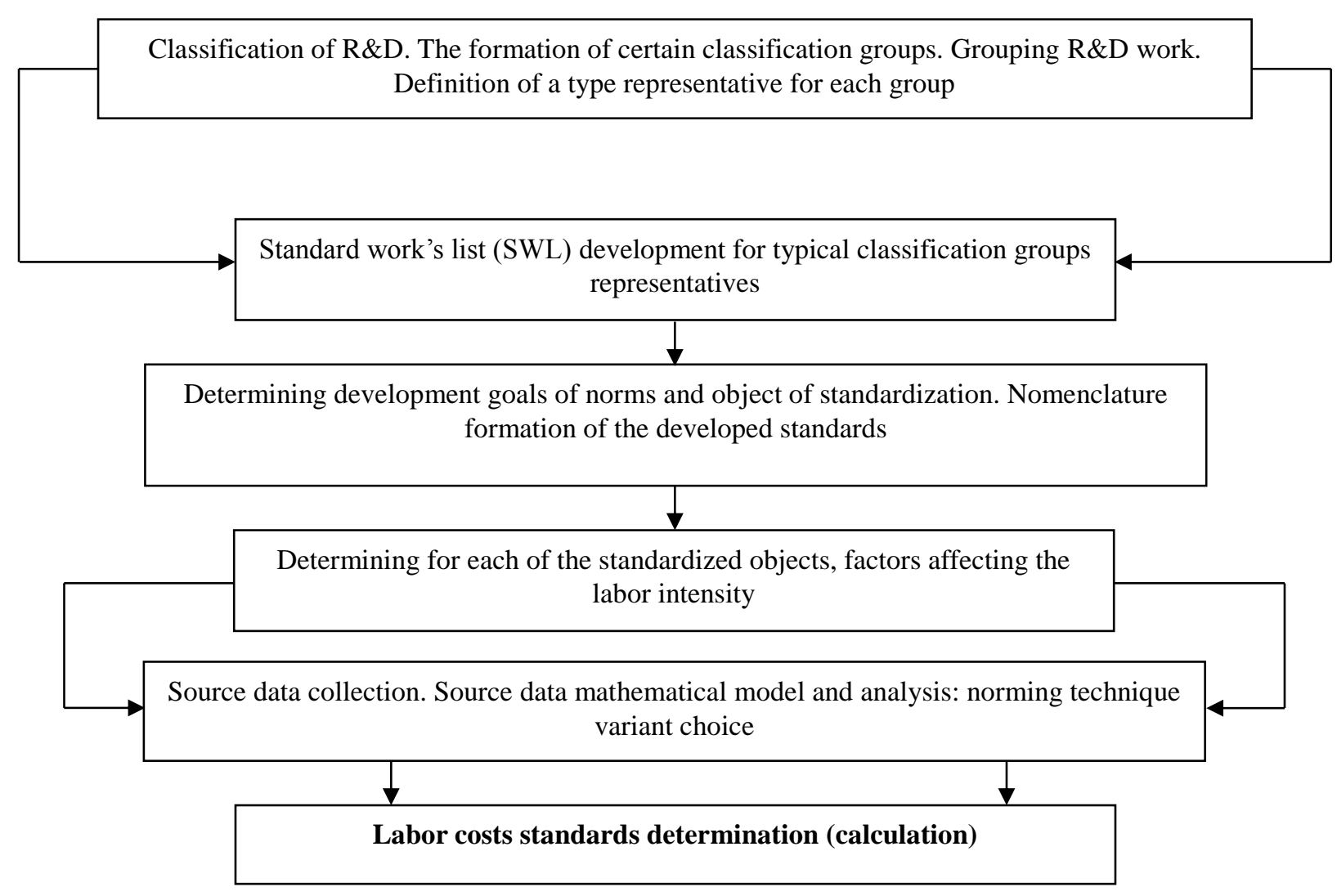

Figure 2. R\&D labor costs standards development algorithm scheme

For research (development) of various technology areas, the classification criteria composition is different. Common to R (D) in all technology areas are criteria that allow to evaluate the organizational and technical conditions for R (D), the technology direction to which R (D) belongs, and also the type of R (D). For R\&D work carried out in order to create radioelectronic equipment (RE), in addition to the specified criteria, criteria are used to evaluate the functional-target, design and technological features of the developed RE (studied objects) and to classify the development (research) objects. To classify development objects, the following classification features are used (Kutukov, 2011):

1) Functional target features:

- $\quad$ RE subclass, RE group, RE subgroup, RE type.

2) Design features:

- RE disaggregation level, parametric series, features characterizing novelty: principles and parameters, design, electronic components and materials.

3) Technological features:

- necessary technology, production volume.

At the second stage of the standards' development for typical classification groupings' representatives, SWLs are developed, and that means one SWL for each grouping. SWL is a set of planning and accounting units of all aggregation levels from stage to procedure, ordered by the sequence of their implementation, determined by the D technology, and reflecting all the main features of this group's D. A planning and accounting unit is understood to be an integral element of R(D) technology, having a final result that can be used in other technology's elements, and planned by terms and volumes. Distinguish between simple and complex planning and accounting units (Ermakova, 2017):

- simple planning and accounting unit is the smallest indivisible planning and accounting unit that does not include any other planning and accounting units; 
- a complex planning and accounting unit is a planning and accounting unit that includes other complex and (or) simple planning and accounting units.

By complexity, planning and accounting units are divided into six hierarchical groups (aggregation levels): stage, step, sub-step, work, procedure, operation. The grouping principle of planning and accounting units by aggregation level is similar to the grouping R\&D's CE principle (Figure 1).

At the third stage of standards' development, standardization objects, standards' types and nomenclature are determined, the choice of which depends on the standardization goals:

- topic's norming as a whole;

- $\quad$ stages', steps', sub-steps' norming;

- $\quad$ works', procedures' norming;

- regulatory framework formation.

In the case when the standardization purpose is to determine the D's labor costs normative volumes as a whole, there can be two possible approaches for solving this problem. The first approach is based on the integrated standards' use at the stages and steps. Stages, steps in this case are the objects of standards' development. The stages' and steps' composition of the standardized D determines the nomenclature of the standardization objects. The enlarged standards are of low accuracy and can only be used for approximate calculations of the planned D's labor costs volumes. The second approach requires detailed execution plan (DEP) development for D. The objects of standards' development are the planning and accounting units of the aggregation level "Procedure" or "Work". The use of such standards allows more accurately than in the first case, estimate the D' planned labor costs volume. Similarly, the problem can be solved for the case when the standardization purpose is to determine the labor costs normative volumes at the stages, steps, sub-steps. For the case when the goal is to normalize work and procedures, standards are developed for the procedures included in SWL for D's classification grouping (Vilensky, Kaloshina, Livshits, Orlova, Smolyak \& Trofimova, 2002).

At the fourth stage, for each of the standardized objects, the nomenclature, gradations, and the scale for measuring factors affecting the complexity are determined. Identification of factors that significantly affect the complexity is carried out by experts. In this case, factors of all types are analyzed: technical, operational, organizational, etc. The number of factors' types and the factors' number of each type are not regulated.

Among the whole set of factors, those that specify the standardized object's complexity to the greatest degree are determined, and these factors' names are put into the standards' catalog. For each of the selected factors, gradations of factor values and a measurement scale are determined. For this purpose, information on factors is analyzed for a number of previously performed research (development) related to one or different R\&D classification groupings, determine the maximum and minimum factor's value, and establish (select) a measurement scale. For a standardized object, the significant factors' values are determined on the basis of labor costs requirements (LCR) (labor costs (LC)), or expertly, they are presented in a dimensionless form and put into the development objects' catalog (Sosunova, Abbazova \& Fadeeva, 2016; Novikov, 2019).

At the fifth stage, data is collected, processed and analyzed on labor costs for previously performed research (development) and planning and accounting units in their composition. The stage's purpose is to create an initial statistical base for the standards' development. The statistical base should satisfy the following basic requirements (Malskaya, 2006):

- source data volume should be sufficiently complete and ensure the of standards' development for all purposes (topic's norming as a whole, stages' norming, steps', etc.);

- $\quad$ source data should be reliable.

The collection of primary information is carried out in relation to the formed R\&D classification groups. To obtain a sufficient amount of primary information, information should be taken over several years on as many topics as possible. To ensure the data's reliability, it is necessary to take into account only the actual R\&D labor costs, discarding all unproductive. The source of information is the planning and reporting documentation on the topics. The information contained in this documentation is subject to examination for the cleaning purpose. After the source data array formation, depending on their completeness and reliability, a norming technique option is being chosen:

- expert method based option is chosen in the source data absence of the necessary completeness and reliability; 
- experimental-statistical method based option is chosen in the presence of statistical data on previously completed topics.

At the sixth, final stage of the standards' development, depending on the chosen method, the labor cost standards for all norming objects are determined or calculated, the nomenclature of which is specified in the third stage.

\section{Method}

The methodology of norming labor costs for research is intended to determine the labor costs normative volumes necessary to carry out planning and accounting units as R's part as a whole. The objects of norming are the planning and accounting units of various aggregation levels as part of the SWL for R. The choice of planning and accounting units to be standardized, the formation of the of norming objects' range for research depends on the norming goals (Kaloshina \& Ermakova, 2015):

- R's norming in general;

- $\quad$ norming of stages, steps, individual works, procedures;

- regulatory framework formation.

For a norming object means a planning and accounting unit, $A_{s}$, represented by a conjunction $\left(C_{f}\right)$ of planning and accounting units of a lower aggregation level, it is required to determine the labor costs standard volume $N_{s}$ for the implementation of a standardized planning and accounting unit (Sosunova, Abbazova \& Fadeeva, 2016).

$$
C(f)=C_{1}, C_{2}, \ldots C_{f}, \ldots, C_{F}
$$

where $f=\overline{1, F}$ is a serial number of the planning unit in the conjunction $\left(C_{f}\right)$;

$F$ is the number of planning units in the conjunction $\left(C_{f}\right)$.

For conjunction $\left(C_{f}\right)$ the statement have to be met:

$$
N_{s}=\sum_{f=1}^{F} r_{s f}
$$

where $N_{s}$ is a labor costs standard volume for the standardized planning and accounting unit $A_{s}$ implementation; $r_{s f}$ is a standard labor costs amount for the planning unit $C(f)$ implementation.

In accordance with formula (2) for solving the main problem, which means determining the value $N_{s}$ it is necessary to determine the labor costs standard volume for the implementation of planning and accounting units $C_{1}, C_{2}, \ldots, C_{f}, \ldots, C_{F}$, constituent $C(f)$.

$$
r_{1}, r_{2}, \ldots, r_{f}, \ldots, r_{F}
$$

$A_{m}$ list of previously completed (basic list) in the former R's planning and accounting units-analogues of the normed planning and accounting unit is determined by the formula (Ministry of Science and Higher Education, 2019):

$$
A_{m}=A_{1}, A_{2}, \ldots, A_{m}, \ldots, A_{M}
$$

where $\mathrm{m}=\overline{1, \mathrm{M}}$ is a serial number of the planning and accounting unit-analogue in the base list; $\mathrm{M}$ is a the number of planning and accounting units-analogues in the base list.

Each of the accounting units $A_{m}$ of the base list includes the conjunction $C(f)$ of lower aggregation planning units. Therefore, the labor costs volume's numerical values for each of the base list's planning and accounting units calculated by the formula (3) can be determined:

$$
N_{1}, N_{2}, \ldots, N_{m}, \ldots, N_{M}
$$

where $N_{m}$ is a labor costs volume for the implementation of the m-th accounting unit.

The problem of determining the quantities $r_{1}, r_{2}, \ldots, r_{f}, \ldots, r_{F}$ is solved for the case when the source data on the labor costs volume for the planning and accounting units implementation performed in previous research, are unreliable or completely absent. Such problem's feature formulation is the need, in the general case, to calculate the relative standards $\mathrm{n}_{1}, \mathrm{n}_{2}, \ldots, \mathrm{n}_{\mathrm{f}}, \ldots, \mathrm{n}_{\mathrm{F}}$ for each standardized object $\mathrm{A}_{\mathrm{s}}$. The procedure for determining the labor costs normative volume $N_{s}$ for the standardized object $A_{s}$ is shown in Figure 3 (Government of the Russian Federation, 2011).

The process of determining the labor costs normative volume includes eight stages.

The first stage is the basic list of analogues $A_{m}$ of the standardization object $A_{s}$ (analogous objects). When 
forming the list $A_{m}$ among research works that make up the classification group, search for research works containing planning and accounting units similar to normalized ones.

At the second stage, the labor costs volumes $\mathrm{N}_{1}, N_{2}, \ldots, N_{m}, \ldots, N_{M}$ for the analogous objects $\mathrm{A}_{1}, A_{2}, \ldots, A_{m}, \ldots, A_{M}$ is included in the basic list.

At the third stage, the conjunction of planning and accounting units $\mathrm{C}(\mathrm{f})$ of a lower aggregation level than the normalized one, which are part of the standardized object and satisfy the condition described in formula 2.

At the fourth stage, an iterative procedure for determining the relative priorities of analog objects is performed based on comparing them with each other for each accounting unit included in the conjunction $C(f)$.

At the fifth stage, based on the obtained numerical values of the relative priorities $p_{m \text { rel. }}^{f}$, a linear programming problem is formed, as a result of which the relative standards' numerical values $n_{1}, n_{2}, \ldots, n_{f}, \ldots, n_{F}$ for the planning and accounting units execution are found $C_{1}, C_{2}, \ldots C_{f}, \ldots, C_{F}$.

At the sixth stage, a new basic list $A_{m s}$ is formed, including the normalization object $A_{s}$. The normalization object replaces the analog-object in the list $A_{m}$, which has the least reliable value of $\mathrm{N}$ (the labor costs volume).

At the seventh stage, for the new basis list $A_{m s}$, an iterative procedure for determining the relative priorities $p_{s}^{f}$ rel. is done.

At the eighth stage, the numerical values of the relative standards $n_{1}, n_{2}, \ldots, n_{f}, \ldots, n_{F}$ and the obtained numerical relative priorities values $p_{s}^{f}$ rel. are implemented into formula (2), which, taking into account the equality:

$$
r_{f}=p_{\text {s rel. }}^{f} \times n_{f}
$$

where $n_{f}$ is a relative norm. Therefore, the formula takes the form:

$$
N_{s}=\sum_{f=1}^{F} p_{\text {s rel. }}^{f} \times n_{f}
$$




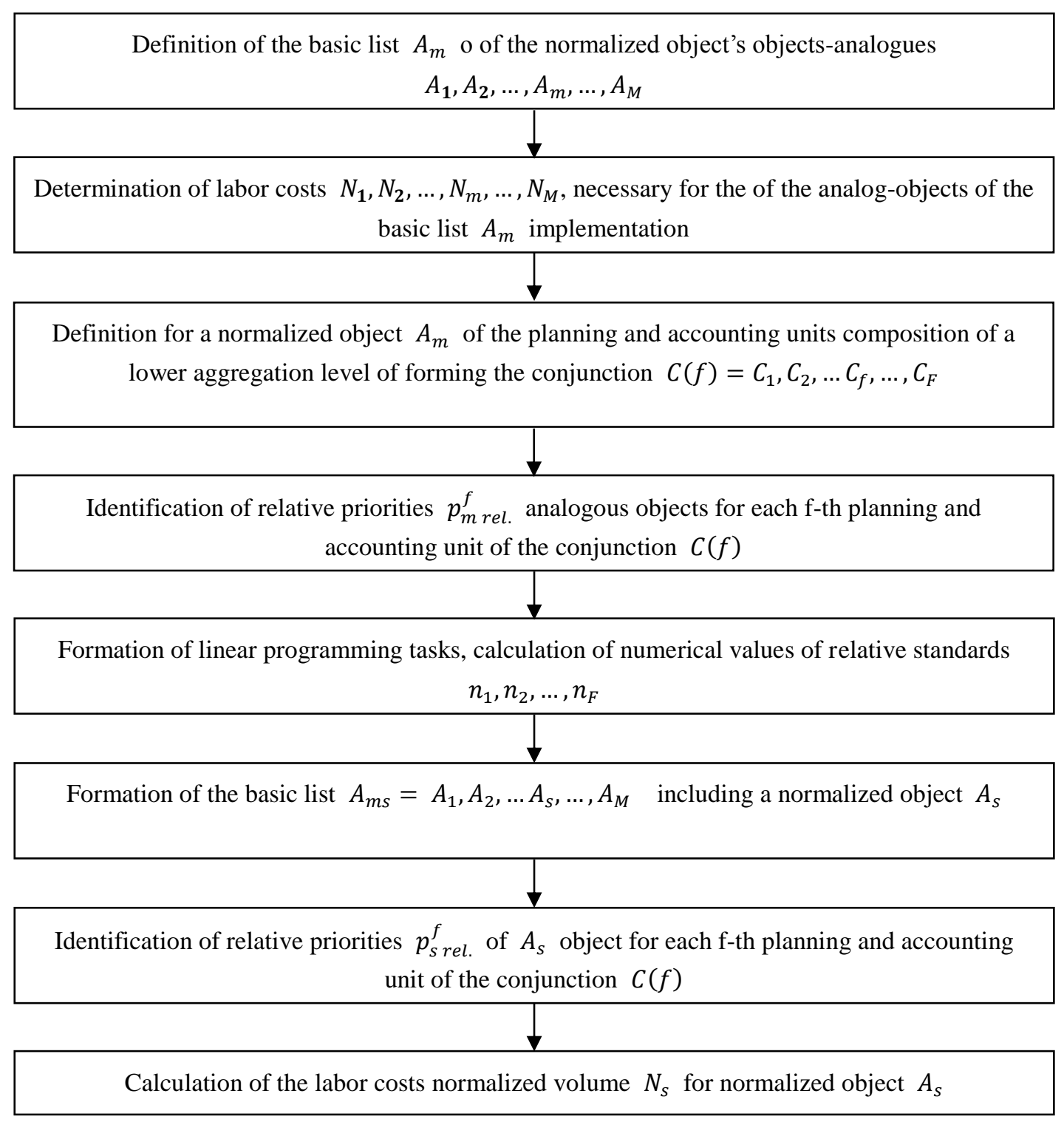

Figure 3. Procedure for determining the labor costs normative volume for a norming object

Normalized D is classified and determined via its membership in any D classification group. On the basis of SWL related to this D group, for the normalized D, DEP is developed, which reflects the scope of work and their relationship (the inclusion of planning and accounting units of lower levels in planning and accounting units of higher levels of aggregation). Depending on the completeness and reliability of the available data on previously performed D, various methods are used to determine the norms: expert or experimental-statistical (Kutukov, 2011).

\section{Results}

3.1 Automated System for Calculating Labor Intensity Forecast Indicators in the Product Life Cycle Information Support

In automated production support systems in accordance with the product life cycle, the following tasks are solved in a varying degree (Bokov, \& Podolsky, 2015; Dmitriev \& Novikov, 2019):

- project data management;

- automated design;

- engineering calculations' and analysis' automation; 
- $\quad$ production technological preparation;

- $\quad$ production planning;

- $\quad$ production system management;

- $\quad$ supply planning and management;

- $\quad$ production processes dispatch control;

- $\quad$ sales and service management.

Existing automation systems for production's technological preparation and the corresponding modules of production systems automated control systems partially solve these problems. However, there are no integrated solutions on the market that allow performing the available tasks' entire list in a unified style. Due to its specificity, the least development now is received by the planning and production technological preparation systems, systems of rationing and evaluation of goods production economic indicators (labor, workshop, overhead and other costs, etc.). Solving norming and evaluating the complexity of manufacturing engineering product problems in modern conditions require automated systems development that could function in an enterprise's single information space and use advanced complex methods for assessing the complexity of engineering product manufacturing (Malskaya, 2006).

The automated support system process is logically based on four structural elements:

1) Product Lifecycle Information Support Database.

The development of custom-made production has revolutionized the automation control means in industry. When each product is configured in accordance with the customer's specific requirements, there is a need to obtain accurate and up to date information about the product from both service and commercial services, as well as from enterprise's the design and technological services. In these conditions, the product becomes ineffective and unacceptable with the usual documentation focused on the products' line, which leads to an increase in the service and maintenance cost. The solution to the problem of meeting the growing user's needs is the use of product data management system, PDM. The Russian PDM "PartY" system allows to solve the whole range of tasks related to the product life cycle supporte.

The PartY automated system fully complies with unified design documentation system (UDDS) requirements and is characterized by good scalability and performance. Using data base management system (DBMS) such as SQL Server (Sybase SQL Anywhere, Sybase Adaptive Server, MS SQL Server, Oracle) to store and search for information, PartY allows to work in a geographically distributed mode, build various reports and link documents with products. A distinctive system's feature is the adjustment to the specifics of the enterprise using the rules for conducting design procedures. The autonomous operation of PartY can be integrated with both DOCS Open and other systems, including the scale of the unit. The autonomous operation of PartY as an enterprise PDM system is also possible.

2) Project planning and monitoring modules.

Any modern high-tech enterprise can exist only under the condition of constant development and adaptation to changing conditions. The key to successful development is the precise goal's formulation and their achievement, in other words effective production planning. In turn, the process of production's technological preparation is an equally important process, which is the basis for planning, since it contains source data (consumption rates, time norms, etc.), the accuracy of which the enterprise's work depends no less. Therefore, it is extremely important to ensure the fulfillment of the preparation and planning tasks in a single complex. At the moment, the best solution for the preparation, planning and dispatching of production is the integrated "TechnoPro" complex and MES system "TechnoPro: Planning", which integrates management and optimization of production activities from the beginning of the order to the production of finished products as a whole, is an effective and convenient mechanism for production processes management automation. Depending on the tasks' scale, such systems as, for example, "Zenith SPPS", "MS Project", "SmartSheet", "Gantt Project", etc. can be used as planning systems that can be part of the "TechnoPro: Planning" complex. The integrated complex "TechnoPro: Planning" allows solving the enterprises' following tasks (Government of the Russian Federation, 2011; Kaloshina \& Ermakova, 2015):

- labor resources efficient using (control over the production activities of personnel);

- $\quad$ increasing the utilization rate of production capacities (optimal equipment load);

- ensuring effective production planning;

- $\quad$ costs reduction for warehouse storage of components and materials; 
- decrease in the volume of work in progress;

- decrease in the number of defects (defects origin points registration);

- improving the customer orders accuracy;

- improving the quality of managerial decisions made (ensuring the prompt provision of necessary management information and reducing the human factor).

3) Modules used to analyze production systems and forecast economic production indicators.

Forecasting modules include pre-forecast preparation of time series, analysis and selection of the most suitable forecasting option for each time series, forecasts calculation. Time series analysis involves collecting statistics and calculating autocorrelation for each time series. The forecast is calculated using the following forecast models (Ermakova, 2017):

- by average;

- according to the trend;

- according to seasonality;

- multiplicative model;

- linear regression;

- additive model;

- seasonal decomposition with preliminary data conversion;

- autoregression;

- neural network.

In the Module for choosing the best forecasting model, the forecasting models are evaluated according to several criteria and the best model is determined in accordance with the specified criterion. List of available criteria:

- error;

- absolute error;

- absolute error \%;

- $\quad$ error \%;

- standard error;

- actual sales dispersion;

- variance error.

4) Modules of technological support for production and technical regulation.

An automated system should contain documentation sets for the following types of standard works (SW): machining, assembly, cold stamping, forging and hot stamping, casting, heat treatment, coatings, welding, soldering, plastic and rubber manufacturing, electrical installation.

System modules should take into account the following requirements:

- General requirements, forms and rules of paperwork according to following state standarts ("GOST" in Russian): GOST 3.1105-84, GOST 3.1118-82, GOST 3.1119-83, GOST 3.1121-84, GOST 3.1122-84, GOST 3.1123-84, GOST 3.1128-93, GOST 3.1129-93, GOST 3.1401-84, GOST 3.1402-84, GOST 3.1403-85, GOST 3.1404-86, GOST 3.1405-86, GOST 3.1407-86, GOST 3.1408-85, GOST 3.1409-85, GOST 3.1428-91, GOST 3.1502-85;

- Rules for recording operations and transitions by: GOST 3.1702-79, GOST 3.1703-79, GOST 3.1704-81, GOST 3.1705-81, GOST 3.1706-83, GOST 3.1707-84.

In the automated mode of system modules operation, operations should be designed, equipment selected, transition texts formed, processing allowances calculated, tools selected, processing modes and time calculated for:

- preparatory-final $\mathrm{T}_{\mathrm{pf}}$;

- incomplete and piece time $\mathrm{T}_{\mathrm{i}}, \mathrm{T}_{\mathrm{p}}$;

- $\quad$ main $\mathrm{T}_{\mathrm{m}}$; 
- $\quad$ auxiliary $\mathrm{T}_{\mathrm{a}}$.

The calculation methods main source is the Interindustry and industry standards developed and published under the control of the Central Bureau of Labor Standards (CBLS) under the Ministry of Labor and Social Development of the Russian Federation.

The interaction between the structural elements of the package is built on a single enterprise database (product information support database) and on structural and technological complexity as a universal indicator of the product's economic parameters. The Informatics Problems Institute (IPI) database (DB) uses both its own structures and representations from databases of third-party systems used at the enterprise. In addition, each individual module of the package has its own data structures that solve local storing and processing information problems. Package's fragments of automated systems are partially implemented in the form of an automated system of technical regulation (ASTR), a system for determining the organizational and technical level of multinomenclature production, a system for calculating project costs, manufacturing parts of mechanical engineering, etc. (Sosunova, Abbazova \& Fadeeva, 2016).

The automated system's basis is the "forecast" module, which will provide a multilevel classification of the training sample product or elements coming to the system input, training and configuration of artificial neural networks, and an approximating unit based on the mathematical apparatus of artificial neural networks. Initially, a test product description is performed using the parameters selected by experts for each conversion applied to the object. Further, after preliminary and basic classification is carried out, when the product falls into one of the basic classes, the classification procedure is performed using the pre-configured Kohonen network for the current basic class. When it is impossible to determine the basic class, the product under study description is refined, or the classification and approximation models are fully tuned for a new type of product. After correlating the studied product with one of the classes obtained on the self-organizing map basis, the product's structural and technological complexity indicator is evaluated using the corresponding trained neural network.

The first step in setting up the structural and technological complexity model is an existing expert group formation or selection, which means that the group of competent specialists whose opinion will be used for evaluating the significant parameters for the technological conversions newly implemented in the production system. Also, the expert group takes part in the products' training set formation, which parameters will be considered as reference and control when setting up the automated system's approximating models and classifiers. After the training sample formation, a phased classification is performed, the result of which are several products' classes, for each of which a neural network approximating model is built and trained (Vilensky, Kaloshina, Livshits, Orlova, Smolyak \& Trofimova, 2002).

The database provides the product's structure formation by organizing links to previously created objects. For example, if a part is included in several nodes, then its model is not copied multiple times, but links to this part are formed. Based on the created assemblies, product documentation can be performed. Moreover, the documents' forms (specifications, material lists, etc.) are presented in the form adopted by the enterprise, and are reduced to formats suitable for transferring to other automated systems.

\subsection{Algorithm for Evaluating $R \& D$ Work Clusters Cost for the Creation and Development of Aircraft's Distributed Systems}

The algorithm is supposed to use various methods for labor cost evaluating (Figure 4). If enough information has been generated to evaluate the costing items expenses, then R\&D's cost evaluation using the costing method will be conducted. As recommendations for improving the methodological provisions of $R \& D$ cost estimation, taking into account the peculiarities of the aviation equipment's distributed systems development, it is proposed:

- to assess labor costs, take into account the regulatory acts requirements that determine the aircraft's distributed systems functioning;

- to use R\&D's works complexity values, calculated on the earlier developed algorithm basis; take into account the difference in the performers' qualifications of each type of work in the framework of R\&D;

- to use the depreciation group's minimum time limit when calculating depreciation; apply accelerated depreciation;

- to distribute depreciation for individual works: at the research stage, in proportion to the performers' wages; at the development stage, by the industrial production personnel intensity;

- to use forecasted deflator indices for evaluating each type's material costs with more than a year R\&D duration. 


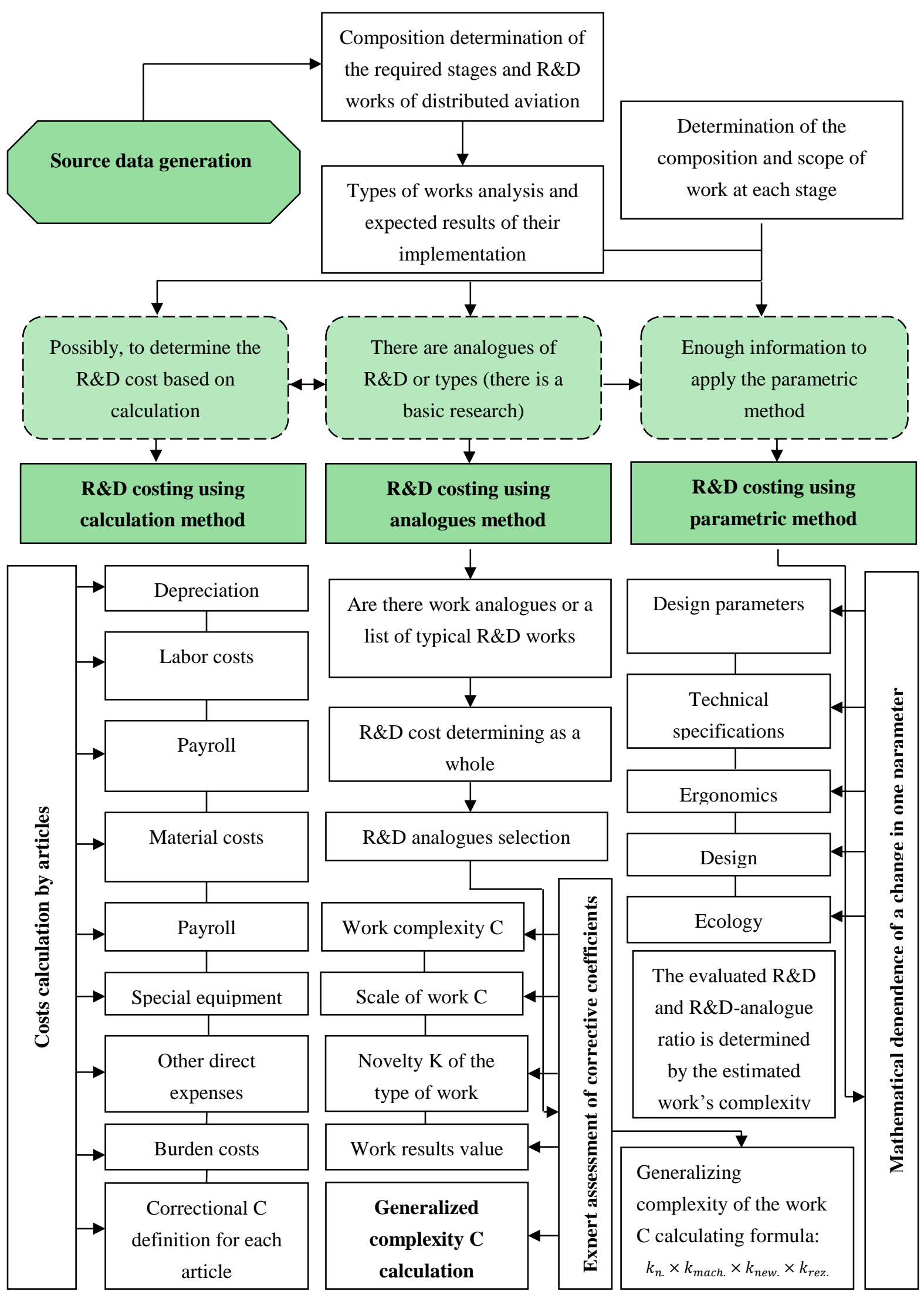

Figure 4. $R \& D$ cluster cost estimation algorithm 


\section{Discussion and Conclusion}

The time costs forecast for the enterprise's product range production in the conditions of engineering products rapid change is necessary and allows to reallocate its resources efficiently and reasonably. Particularly significant becomes the forecasting role when introducing a new production nomenclature. At this stage, for the various enterprise's services there is a significant set of tasks that must be completed with minimal time loss. In this regard, the methods development for the time costs reasonable prediction for a new production range manufacturing is so much relevant, both from a practical and scientific point of view. All this directly affects the production systems engineering efficiency and affects not only the norming issues, but also makes it possible to increase the managing production resources solving problems efficiency. In a competitive market, a reasonable predictive knowledge of self-costs gives the company the opportunity to determine its nomenclature scope and avoid developing knowingly loss-making products. Consequently, to improve the effectiveness of R\&D, the following things are necessary:

1. The choice of methodology for determining the enlarged norms of R\&D labor intensity should be based on the analysis of the state of the regulatory and statistical base of Scientific Production Association and availability of the analogues. If there is no information and calculation base, the methodological solutions for developing standards are individual.

2. Efficiency of use of production resources at carrying out of R\&D can be provided by development of norms of labor intensity, as labor intensity indicators are the basis for calculation of the prime cost of scientific development and determination of the price for it. The way of formation of norms is defined by specificity of a theme, degree of complexity and novelty of a developed product, presence of products-analogues, and reliable statistical base.

3. Regulation of labor and production costs, as well as control over timeliness of stages of development should be provided on the basis of operational accounting of actual values of controlled indicators.

The application of the stated method of normalization of labor costs for R\&D works in determining the labor intensity will allow forming an objective assessment of the labor intensity of the planned R\&D and will contribute to the efficiency of spending budget funds allocated to the scientific justification of the development of scientific and technical and production-technological base of organizations.

As shown by well-known domestic and foreign scientists and manufacturers studies, time spent forecast is very popular, which would be based on methods that would allow receiving such costs with sufficient accuracy even at the developing design documentation stage or importing it from the customer. A research review in this area showed that this issue was addressed in the analogy methods development direction that do not provide sufficient accuracy. The machine-building complex enterprises are interested in the costs forecast at the development decision making stage of a certain product range in production with a no more than $20 \%$ error. The most adapted to these problems solving is the structural and technological complexity theory, which allows calculating the products' manufacturing intensity based on their properties' evaluation. This does not require good's production technological preparation or its experimental production.

In the current situation, the definition of normative indicators of labor intensiveness is necessary for more effective management of a scientific organization for many reasons: they are a tool for planning research work and its cost; labor standards are a tool for management accounting and labor cost analysis; labor standards are a necessary prerequisite for determining the effectiveness of a researcher's work and 'linking' the compensation to the results achieved; labour standards are one of the most important incentives and should be the basis for the system of stimulating productive work of scientific workers.

The automated system of calculation of prognostic indicators of labor intensiveness offered by the authors takes into account uniqueness of the process of $\mathrm{R} \& \mathrm{D}$, individual characteristics both of it and its executors, allows to consider all objective factors and risks influencing performance of the scientific research project and reception of results of work.

\section{References}

Bokov, S. I., \& Podolsky, A. G. (2015). Principles for evaluating the research intensity carried out in the electronic component base development interests. Armament and Economics, 1, 54-61.

Dmitriev, O. N., \& Novikov, S. V. (2019). Concept of organization and functioning of integrated electronic infosphere of reporting on R \& D works' results. Amazonia Investiga, 8(21), 87-95.

Dmitriev, O. N., \& Novikov, S. V. (2019). Organizational and economic polystructure of innovative projects implementation. Amazonia Investiga, 8(20), 180-187. 
Ermakova, O. V. (2017). Development of principles for the formation of clusters based on the stages and types of works R\&D at the creation of distributed aircraft and aviation systems. Economics and Entrepreneurship, 5(82), 528-532.

Government of the Russian Federation. (2011). Decree of the Government of the Russian Federation of February 25, 2011 №. 107, edited on August 26, 2013, № 739. On approval of the Regulation on recognition of International Financial Reporting Standards and Clarifications of International Financial Reporting Standards.

Kaloshina, M. N., \& Ermakova, O. V. (2015). Cluster modeling in labor input of R\&D in the aerospace industry. Management of Economic Systems: Scientific Electronic Journal, 1(73), 23.

Kutukov, D. S. (2011). The use of clustering methods for processing news flow. Engineering: problems and prospects: material of international scientific conference. St. Petersburg: Renome.

Malskaya, I. R. (2006). Determining the place of implementation of R\&D and SW. Bulletin of the Ministry of Taxes and Duties of the Republic of Belarus, 25, 24-26.

Ministry of Science and Higher Education. (2019). Federal target program " $R \& D$ in priority areas for the development of the scientific and technological complex of Russia" for 2014-2020. Retrieved from http://fcpir.ru/

Novikov S. V. (2019). Clusters in modern innovations of the economy of the Russian Federation. Espacios, 40(25).

Sosunova, L. S., Abbazova, L. R., \& Fadeeva, A. O. (2016). Standards for cost accounting for R\&D. Young scientist, 21, 498-501.

Vilensky, P. L., Kaloshina, M. N., Livshits, V. N., Orlova, E. R., Smolyak, S. A., \& Trofimova, N. V. (2002). Brief practical guidelines for evaluating the investment projects' effectiveness (guidelines). The official edition. Moscow: Chamber of Commerce and Industry of the Russian Federation. 